\title{
International Challenges to Transformational Government: Enhanced Project Management Identifies Need for Existential Change
}

\section{Shauneen Furlong}

Ottawa, Canada/Liverpool, United Kingdom, SFurlong@territorialcommunications.com

Abstract: The case for transformational eGovernment continues unabated; impatient stakeholders are more demanding; people, process and content are profoundly impacted; opportunity is rampart - but so is risk and complexity; still, transformational eGovernment remains more theoretical than practical. Execution has faltered and relief is not obvious.

Enhanced project management has made progress in advancing eGovernment by applying enhanced project management in a holistic manner so that project activities are fully integrated with on-going operational activities: all with an emphasis on measurable results and outcomes.

This paper, however, concludes that there is another dimension to the transformational eGovernment navigation tool-kit that coalesces with enhanced project management and creates a multi-dimensional approach to transformation; it is existential change leadership that focuses on human mindset behaviour.

Thus, the next step in the research is to examine a two-pronged approach (enhanced project management and existential change leadership) to respond to the challenges and barriers that have long impeded transformational eGovernment progress and the accountability vacuum for the elusive transformational breakthrough results.

Keywords: eGovernment, transformational eGovernment, project management, change management, existential conscious leadership

\section{Introduction}

Transformational eGovernment is the continuous innovation in the delivery of services, citizen participation, and governance through the transformation of external and internal relationships by the use of technology; especially the Internet. When introduced, it offered the hope and promise to revitalize and modernize public services; reinvigorate and improve services to citizens, business and governments; and create an exciting environment for employees to work and contribute. Countries 
world-wide are inexorably engaged and urged forward by both push-and-pull motivational pressures to use technology to improve democratic participation, social harmony, and economic sustainability. However, it has not achieved the international world-wide success anticipated. eGovernment has high rates of failure; by some measures, more than $60-80 \%$ are partial or total failures (United Nations, 2003).

eGovernment, and especially transformational eGovernment, progress remains slow and halting and shackled to time-honoured approaches to project management, especially in the information communication technology (ICT) domain. eGovernment is the traditional, transactional and service focused improvement on Government operations through the application of ICTs, whereas transformational eGovernment encompasses the reform and modernization of the business process reengineering opportunities and enterprise-wide reform, as well as what and how the government achieves its mandate. Ineffective project management is one of most significant reasons for transformational eGovernment failure (Aikens, 2012b; Misuraca, 2009). There are a number of reasons and examples for transformational eGovernment project failures, including the lack of capacity to manage unanticipated transparent and concealed organizational opposition; the inability to effectively and precisely identify current, changing, disparate, and conflicting key information requirements; and lack of insight into the obstacles in obtaining parochially coveted information. These are in addition to a recent (2012) review of literature (developed and developing countries) that outlines the most common issues and problems that cause eGovernment failure to be cultural barriers; infrastructure; resources; socio-economic barriers; security and privacy; and e-integration (Zhao, 2012).

\section{Background}

Transformational eGovernment has not been the success hoped for around the world and a number of the barriers preventing success have been identified and analyzed (Weerakkody, Janssen, \& Dwivedi, 2011; Sharif \& Irani, 2010; Ziemann \& Loos, 2009; Dawes, 2009; United Nations, 2010; United Nations, 2008; World Bank, 2002; Nordfors, Ericson, Lindell, \& Lapidus, 2009; Oxford Institute, 2007). It has been harder, slower, and more complicated to deliver than what was originally expected, specifically from a business transformational agenda (BCS Thought Leadership, 2005; Roy, 2006). Transformational eGovernment promised hope for government transformation, public sector renewal, and revitalization of the role of bureaucracies in the 21st century. eGovernment delivered primarily on the transactional success of using the Internet to allow citizens closer and more direct access to government programs (Weerakkody, Janssen, \& Dwivedi, 2011); important and valuable, but not of the significance and benefit that was predicted. Transformational eGovernment remains slow and halting (Aikins, 2012b) and shackled to the time-honoured approaches of managing existing organizational assets rather than reaching out to create new management capacities that business transformation demands and technology affords.

Even in Canada, where eGovernment was rated number one in the world for five years in a row by Accenture (Accenture, 2005, 2006, 2007; Government of Canada Foreign Affairs \& International Trade, 2006), it is seen as being primarily a transactional success as opposed to a transformational 
one (Roy, 2006). Internationally, there has been a high and critical failure rate related to IT solutions (Aikins, 2012b; Fraser, 2006). More recently the failure in IT solutions that was the bane of transactional processing is now appearing in eGovernment initiatives (Heeks, 2008; Arif, 2008; Janowski, Estevez, \& Ojo, 2007; Aikins, 2012b). eGovernment failures are often hushed up (Heeks, 2003) and as Misuraca (2009) points out, the majority of eGovernment projects are failures as high as $70-80 \%$ and are not meeting the breakthrough expectations. Failures are costly; as per Irani, AlSebie \& Elliman (2006), the United Kingdom Parliamentary Office of Science and Technology reported that cancelled or over-budgeted eGovernment projects were greater than 1.5 billion British pounds.

There are a number of reasons for the lack of transformational eGovernment success, including unanticipated organizational opposition, difficulties in communicating requirements and obstacles to obtaining information from different government departments and agencies (Kamal, Weerakkody \& Irani, 2011). However, there is some support for the belief that one of the most significant reasons for transformational eGovernment failure is ineffective project management (Aikins, 2012b; Misuraca, 2009). The literature and this chapter refer to the dearth of peer-reviewed information on the effective role of project management and its impact on transformational eGovernment project success even though there are non-peer-reviewed business publications and country audits (British Computer Society, 2004; Fraser, 2006) that identify ineffective project management as an important cause of ICT failure.

The finding based on the literature review is that ineffective project management is a leading cause of eGovernment failure. The reason for this ineffectiveness is a result of the use of the traditional project management methodologies that do not meet the demands of transformational eGovernment for results, accountability, and problem solving.

The following introduces the current project management approach as it applies to project management as a discipline and science, and why it has been less than effective. It does not undertake to examine in detail the limitations of the project management approach (processes and knowledge areas are discussed below) to the complexity involved in managing and successfully delivering an eGovernment project. Governments continue to rely heavily (in the absence of an alternative) on the codified concepts of project management in its quest to develop and implement transactional and transformational eGovernment projects in spite of the project high failure rate.

This section discusses project management as a holistic discipline as opposed to an examination of the specific criteria and iterative approaches used in developing project management methodologies. Project management science is described in the North American focused PMBOK and the European focused PRINCE2 (2009). The fundamental scientific codification sets out project management concepts in terms of project processes and project knowledge areas. By cycling through the processes and knowledge areas, project management spans the full array of information that must be merged to develop an eGovernment project. PMBOK 2008, the 4th edition describes the process groups to be initiating, planning, executing, monitoring and controlling, and closing. The knowledge areas are integration, scope, time, cost, quality, human resources, communications, risk, and procurement. 
Project management as derived from generic project management methodologies is a systems approach to planning scheduling and controlling project activities; it began its modern accelerated growth in the 1960s (Kerzner, 2001). The systems approach creates a project management framework that is constructed from process groupings and knowledge areas. The implementation of this approach ensures that the work of project management activities is performed efficiently and effectively and is measured by such features as planning, cost, schedule management, scope control, and communications.

In transformational eGovernment, the project management systems approach is not enough. Instead, in transformational eGovernment, project management must discover the interrelated sets of challenges, barriers, and changing conditions that impede transformational eGovernment project success and respond to and cope with them from a "results achieved" perspective. The project management systems approach must become a basic entry level to the transformational eGovernment project management regime. Now, project results and change management must become the project drivers that are measured by the effective management of objectives, stakeholders, clients, technical and subject matter experts, resources, and functional support services (Kerzner, 2001).

There are many reasons cited for project management failure and many of them are attributed to one or more breakdowns in the traditional project management systems approach (Aikins, 2012). Nevertheless, when a project finally meets key stakeholder (user) requirements, many other project short-comings are overlooked such as cost overruns, late schedules, and scope creep. However, in the author's opinion, transformational eGovernment project management must result in success by ensuring that project management evolves from a system activity approach to a system results approach that must meet key stakeholder expectations. This all starts with identifying an interrelated set of transformational eGovernment project barriers, challenges, and change complexities. This research is focused on informationally enhancing the project management process in order to upgrade the traditional systems activities approach and support the project results orientation.

To address the difficulties currently experienced specifically in eGovernment projects, it can be argued that modern project management growth which began in the 1960s (Kerzner, 2001) now needs to be radically accelerated; become less process bound, more results driven, and change oriented. Transformational eGovernment project management could take on the functions and features of other management professions similar to the example of accounting and finance. By comparison, accounting is subsidiary to finance and project processes are subsidiary to project results. Results should far outweigh processes.

Transformational eGovernment project management has adopted the broad project management components; such as standardized frameworks, governance, certifications, and qualifications that were developed in the past and in different industries. Academics, researchers, and practitioners continue to compile knowledge, skills, tools, and techniques that form the basis of the science of project management. This science has been encoded into project methodologies or guides that are generally accepted by theoreticians and practitioners and they are heavily promoted by government 
decision-makers and contracting authorities. Most practitioners, however, and even some academics, perceive and act as though the prime purpose of project management methodologies is to manage administration and compliance rather than support and guidance (Wells, 2012).

Hence, transformational eGovernment project management must accelerate the trend in project management. The systems-based approach incorporated in the generic project management methodologies is not enough for transformational eGovernment. Instead, in transformational eGovernment, project management must become more results focused and less prescription focused. It must discover any interrelated and holistic sets of challenges, barriers, and change issues that impede transformational eGovernment project success; it must respond to and cope with them from a "results achieved" perspective. The project management systems approach must devolve to a basic entry level to the transformational eGovernment project management regime and project results and outcomes must be the project drivers that are measured by the effective management of objectives, stakeholders, clients, technical and subject matter experts, resources, and functional support services (Kerzner, 2001).

Of the reasons cited for project management failure, many of them are attributed to one or more breakdowns in the traditional project management systems approach (Aikins 2012b). Transformational eGovernment project management must result in success by ensuring that project management evolves from a system activity approach to a system results approach that starts with identifying an interrelated set of transformational eGovernment project barriers, challenges, and change requirements. This research is focused on informationally enhancing the project management process in order to upgrade the traditional systems activities approach and support the project results orientation.

To address the difficulties currently experienced specifically in eGovernment projects, it can be argued that modern project management growth that began in the 1960s (Kerzner, 2001) now needs to be radically accelerated; become less process bound, more results driven, and change oriented.

\section{3. eGovernment Project Management Methodologies: Problems and Solutions}

The current more popular international project management methodologies, PRINCE2 and PMBOK, along with a litany of others, do not meet the needs of eGovernment. eGovernment failure is disappointing and much research has been dedicated to examine why and if project management could be the culprit. Clearly, project management plays a significant role. This paper introduces the proposition that current parlance and management culture accepts that the science of project management is only enacted once a project has been identified.

Inexplicably, common practice does not acknowledge that it is the application of the science of project management to any operational endeavour that creates a specific project. The project is born through the application of the project management principles by bringing rigour, discipline, and specificity to a challenging and complex, though often vague, operational endeavour and objective. 
In addition, the science of project management expressed through popular methodologies does not address nor assist with the synergistic compendium of ten barriers and challenges to international eGovernment success recently studied (Furlong, 2011; Furlong, 2012). Furthermore, the discipline of change management is not one of the knowledge areas in the generally accepted project management methodologies.

This paper describes these barriers and challenges and it introduces how project management methodologies fail to address them and how an eGovernment tailored project management solution could mitigate them. In fact, this paper states that these elements must be tackled in order to advance the transformational eGovernment agenda that so many countries strive to attain. As well, this paper addresses the need for effective change management through existential change leadership.

This section outlines the current situation and the inadequacy of the current project management methodologies and their failings; introduces the compendium of ten barriers each requiring attention; and offers preliminary solutions to governments and commercial organizations to digest.

In these world-wide methodologies and other more parochial ones, methodologies, time-honored project management processes associated with project integration, scope, schedule, cost, quality, resource, communications, risk, and procurement are often used as safeguards that split management and control of the projects and thereby water-down accountability for project development and implementation success. In no case is there a domain within the methodologies that directly and specifically provides the transformational eGovernment project manager with the tools to cope with the intrinsic problems that impede transformational eGovernment (Furlong, 2011; Furlong, 2012).

The objective of this paper is to revamp project management methodologies by transforming them from process-bound mechanisms to a problem and results oriented instrument. Akin to the early medical profession's emphasis on procedure (i.e., in order to preclude the adage that the operation was a success but the patient died) the project management profession has too long suffered from the use of project management methodologies that focus on procedures and processes instead of those that focus on results and accountability. Futuristic transformational eGovernment project management methodologies must contribute to the successful management of transformational eGovernment projects. They must move well beyond the generic body of knowledge that is generally recognized as good practice. Instead, the enhanced methodologies must address the very caveat that existing methodologies hedge against; that is, the embracement of the responsibility for management to obtain successful results for transformational eGovernment projects. The enhanced methodologies must reach above and beyond the goals to provide professional project management certification; standardization of processes, skills, tools, and techniques; and ethical codes of conduct. They must address a higher objective. The required methodology must enhance the science of transformational eGovernment project management so that the project team can be held accountable for results achieved. The project manager and team are not stewards of the administrative procedures; they are responsible for project success and outcomes. 
Various key transformational eGovernment organizations (United Nations, 2010; West, 2007) have completed studies that identify the causes of transformational eGovernment project failure and, just as importantly, they have identified, described, and analyzed the reasons for project development and implementation success. Current project management methodologies unwittingly allow the project manager to escape his accountability by retreating behind the mantra - "we' re on budget; we're on time; you changed the requirements." These processes protect her or him at the expense of project results-oriented success as opposed to process-oriented success.

Current transformational eGovernment project management is built on the broad project management components such as standardized frameworks, governance, certifications, and qualifications; and administrative tools and techniques that were developed for a different time and for indifferent industries, some of which no longer exist or are radically changed like agriculture, auto making and mining coal. These project components are focused on the techniques and science of project methodology as opposed to the successful delivery of project products, services, and results; and on the solving of problems and barriers to project success.

For example, current project methodologies related to project cost management involve estimating, budgeting, and controlling costs. These processes, however, can lead to the creation, control, and analysis of an array of data points that can overwhelm and even misinform the project manager, the project team, and key project stakeholders. Other project management domains such as project quality management include process elements such as cost benefit analysis, control charts, bench marking, statistical sampling, and flowcharting

The point is that ineffective project management is one of most significant reasons for transformational eGovernment failure (Aikens, 2012b; Misuraca, 2009), and that the focus on project methodology instead of project results is the root cause of ineffective project management. Methodology trumps results.

Time-honored project management administrative processes such as scope, schedule, cost, quality, resources, communications, risk, and procurement often tend to split the management and control of the projects and dilutes the accountability for project success.

Nevertheless, enhanced project management redirects the definition of projects (particularly ICT work) towards results. It means existing in a futuristic milieu of complexity and uncertainty wherein it is the application of the science of project management to any endeavor that creates a project, not the project start-up definition. Futuristic projects will be created, they will not be defined; they will be created by evolution, unintended consequences, and responsive iteration that solves problems and produces project results. Futuristic projects will encompass a significant component of existential change leadership to cope with the behavior and mind-set uncertainty that permeates projects in an ever-faster changing environment.

In eGovernment project management enhancements, management of eGovernment projects would focus on project problems rather than methodological processes. The enhanced project management solution would provide the tools, techniques, and mind-sets to account for the impact 
of the holistic, synergistic challenges and barriers that surround and influence eGovernment projects.

\subsection{Definition of the Compendium of 10 International Challenges to Transformational eGovernment Success}

The following summarizes the author's compendium of ten international challenges and barriers that prohibit eGovernment transformation, and offers enhancements to the project management process to address these limitations in an eGovernment environment.

\subsubsection{Requirement to Manage Diverse and Conflicting Stakeholder Interests within a Governance Framework}

Stakeholder interests are usually conflicting because eGovernment applications are usually developed with one or more departments and central agencies. Each of these departments and agencies has a unique legislative mandate, accountability regime, culture, history and background, and more recently security requirements.

\subsubsection{Challenge to Continuously Adapt to and Blend Technology, People and Processes}

Today's system environment is more organic that it was in the past; previously, system solutions were applied to a corporate service environment. Today's systems are at the core of company performance, not on the periphery. They are significantly affected by evolving priorities and circumstances, and are more integrated with the operational environment including technological developments, the capacity of the resource experts, and constantly changing and evolving business processes.

\subsubsection{Outdated Business Models that Reward Traditional Applications}

Most business models do not recognize that collaborative and unprecedented solutions do not meet the criteria for performance measurement targets, accurate costing and resource utilization, and work plan deliverables whose solutions are not known until they are negotiated and well into the implementation stage. Promises of cost- and resource reduction along with improved efficiency and effectiveness gains the funder's attention more than promises of transformation and innovation.

\subsubsection{System Development Models Affected by Political Realities and a New Relationship with the Private Sector}

Most system development models do not recognize the "stop and start" reality of projects affected by political cycles and funding priorities, and the need for system development fragments to be reused instead of continuously "starting over." Though cancelling projects is generally due to changing systems objectives, it is critical to recognize the waste of precious resources and time, and 
the inability to recover and reuse these efforts. However, public service has been impacted significantly through private sector contracting and outsourcing arrangements. The integration of private and public sector resources is now mandatory.

\subsubsection{Lack of Access to Lessons Learned and a Body of Knowledge for Government- Wide Projects}

Project managers are designing and implementing system solutions that are often unprecedented and government wide, and yet they have no facility to access the knowledge nor benefit from the experience gained from other project managers in similar circumstances. The problem is that there is no way to harness previous experience and no demand to conduct and access lessons learned.

\subsubsection{Promises of Interoperability, Integration, and Cost and Resource Savings}

The eGovernment environment is predicated upon a collaborative and partnership-based environment that requires sharing both work and accountability responsibilities, and it is usually argued (and ultimately funded) under a banner of promised cost savings and resource reductions.

\subsubsection{Proliferation of Information and the Challenge to Judiciously Access and Manage Information}

The information age exacerbates project management because of the massive and exponentially produced data that must be sorted out to effectively implement system solutions. The interconnectedness of information and system requirements is so overwhelming that projects suffer from the weight of information. Mining through this data to retrieve the relevant information produces a "spin and churn" that can be non-productive; and this, along with the lack of authoritative control to wind through the layers of information, can derail the project.

\subsubsection{Lack of a Comprehensive Holistic Approach to Project Management as the Driving Force}

Project management often plays the role of arbitrator, as it is often the agent that brings the disparate parties together to deliver a solution that was not driven by either party. This is usually the case with citizen centric applications as they cross the program interests of each of the contributing organizations. Project management needs to drive the solution to change the business processes of the affected departments and turn the solution into a government wide enterprise.

\subsubsection{Limited Access to Vital Subject Matter Expertise}

Within governments, knowledge is either so vastly spread or not available that it is difficult for the project manager to understand the implications of systems design. The knowledgeable personnel are difficult to locate and approach given hierarchical and organizational limitations, and are frequently reassigned and no longer accessible. 


\subsubsection{Organizational Environment not presupposed to Enterprise-Wide Transformation}

Departments do not necessarily act as units of a government enterprise; they are vertically based with individual objectives and resource reward mechanisms. Accountability of each department is to its Minister and senior officials, and to the government acts for which it was created.

\subsection{Description of the Potential Project Management Improvements to Address the Compendium of 10 International Challenges to Transformational eGovernment Success}

The following discusses the key enhancements required to project management methodologies to transform them from administrative and compliance processes to results and accountability driven mechanisms.

\subsubsection{Requirement to Manage Diverse and Conflicting Stakeholder Interests within a Governance Framework}

Project management within transformational eGovernment is currently a staff function that incorporates the established project management methodologies that are in use throughout the government project centers of excellence or other such government management control units. However, this staff function must integrate with the work standards and processes applicable to particular governmental operating units. The interaction of the project staff function and the operating unit line function is a key stakeholder requirement, particularly when the situation is complicated by conflicting stakeholder interests.

The existing methodologies handle this requirement by leaving the project manager and team to sort out the procedures for working amid the danger of duplicate activities, unclear or vague responsibilities, and confused reporting lines. They do little to ensure that senior and other appropriate levels of management effectively participate in the development, delivery, and operations of transformational eGovernment portfolios of programs and projects. Rating and weighting the impact of stakeholders throughout the life of the project is key to project management success.

The project initiating and planning processes described in the project management methodologies do not effectively lay out how the project team can gain a complete understanding of the existing transformational eGovernment processes and how the stakeholders interact externally and internally. The process of collecting requirements and creating a project scope document and a work breakdown structure does not sufficiently take into account the impact that stakeholders have throughout the life of the project. The scope of the business changes and the associated use of ICTs change.

An information enhanced project management aid could categorize and "weigh" the stakeholders' influence. It could relate their interests to reporting requirements. It could monitor 
and incorporate changes to their interests and changing degree of influence. It could provide "intelligence" to the project manager on the implications of accommodating changing interests, e.g., impact on other interests and additional time, cost, and reporting requirements. It could highlight to the governance committees the complexities and interdependence of stakeholder interests and the impact on project success and accountability without impeding development. It could highlight, for example, the gap between the interest in considering a government as a single enterprise versus the reality of managing different and competing departmental or ministerial interests and accountabilities. It could also relate interests of the delivery agent (responsible department) with the product; for example, to highlight the inappropriate assignment of accountability to a third party not directly involved in the product line.

\subsubsection{Challenge to Continuously Adapt to and Blend Technology, People, and Processes}

Transformational eGovernment projects are dependent upon robust and flexible ICTs; therefore, transformational eGovernment project management methodologies should include specific procedures to reflect this reality. The procedures should ensure that project managers consult with industry to test the viability of the proposed ICT enabled change, outline the need for a comprehensive and well-evidenced examination of the use of applications for meeting requirements of proposed transformational changes, and include an open and constructive relationship with ICT suppliers and providers. ICTs need to remain aligned with eGovernment technology, people, and processes.

An informationally enhanced project management methodology could highlight the impact of systems and projects on organizational business processes and the issues associated with personnel revising their workplace practices. It could assist in mapping and managing the business process changes resulting from the implementation and evolution of the project. It could also relate the organizational objectives to those particular practices and identify potential technology enabled support; for example, offer an automated checklist to the project manager to recognize the organizational and personnel impact. It could revisit the changes and implications along the project implementation process as they are not static and are adjusted as the project evolves. Ultimately, technology could be designed to contribute to the core performance as these systems form the new basis of the organization's capacity to meet its mandate.

\subsubsection{Outdated Business Models that Reward Traditional Applications}

Transformational eGovernment business models must incorporate the decision-making structure that ensures strong and effective leadership of the ICT effort in support of the business change. Current practices too often reward applications that are easier to measure or understand or cost; not necessarily criteria that leads to complicated innovative changes for a transformational objective.

If the feasibility analysis and project approval process could become part of the overall project management methodology, technological improvements could be developed to help support a shift in the business model criteria to fund the more controversial eGovernment projects. This could 
involve changing the criteria from performance specificity and delivery measures to rewarding more innovative and transformational-based applications.

\subsubsection{System Development Models Affected by Political Realities and a New Relationship with the Private Sector}

Key project stakeholders are interested in a project's results and products rather than the procedures that were used to carry out the project. Project delivery is a product that enables sponsors to assess the rate and quality of progress; and it permits the users to ascertain that their original request represents their actual needs and reflective improvements. The project management methodology could be expanded to subsume system development approaches that meet partnership and transformational solutions. Technology could be provided to assist the management of informationbased projects, which would address the system elements and project management environment, and contribute to the negotiated effort of finding and delivering a project-based solution.

System development and the identification of requirements has become a more "moving target." The relationship between government officials who express their requirements and the private sector capacity to lock them down is strained. The scope and requirements shift is due to changing political interests, funding levels, relationships, accountability regimes, resource availability, and individual influences just to name a few; and this is becoming increasingly difficult for the private sector to carry the cost of chasing requirements.

\subsubsection{Lack of Access to Lessons Learned and a Body of Knowledge for Government- Wide Projects}

There are many reasons why lessons learned are not a factor: lack of time; incentives; resources; management support; and the capacity and knowledge to collect, store, and access the information. Useful lessons learned often focus around risks, issues, change requests, and ICT provider concerns. But just as importantly, methods of ensuring that project managers see the value in applying lessons learned to the uniqueness of their specific project. They must include their evaluation in the scope of "getting things done." Analyzing lessons learned, in the form of a formal literature review, for example, often results in getting things right the first time.

Recent popular language discusses a "wicked problem" to describe a problem that is difficult or impossible to solve because of incomplete, contradictory, and changing requirements that are often difficult to recognize. The term "wicked" is used, not in the sense of evil but rather its resistance to resolution. Moreover, because of complex interdependencies, the effort to solve one aspect of a wicked problem may reveal or create other problems. Project managers are rewarded for getting things done, and in this current regime action is better than thought or discussion - the perceived error of focusing on doing as being more important than reflecting. But lessons learned can lead to correct action and contribute to getting these things done and they can avoid the cost and effort of project rework through planning, training, and communicating. 
Lessons learned are not just theories; they can achieve results and cannot be ignored as they have in the past. The new methodology would ensure that the reflection on lessons learned would become inherent.

A key feature where additional information could benefit the project manager is in having access to the experience and knowledge attained from actual "on-the-ground" applications. The project management methodology could be expanded to support the overall project management and implementation of new solutions, and contributing to building a repository of experience could be of immense value towards the successful implementation of future projects. This approach could encompass the need to access and document experiences from individual projects for a historical database but, more importantly, targeted as the agent to influence the design and implementation of future projects.

\subsubsection{Promises of Interoperability, Integration, and Cost and Resource Savings}

Interoperability, integration, and cost and resource savings in transformational eGovernment requires a multi-layered, multi-faceted backroom technology that is required to participate in a technology-driven public sector economy, and yet delivering upon pre-established savings or systemic approaches before deliverables are available often leads to inaccurate estimating that damages the transformational agenda.

The project management methodology could be strengthened to provide project managers and governments with the tools to achieve interoperability and integration. (Focusing on achieving cost savings is another matter, and perhaps not reasonable in the short term due to the high costs required to design and implement new systems.) Using technology to have access to the information required to deliver on interoperability and integration would be extremely helpful to the project manager. Having automated access to an understanding of the systems and processes required to accomplish interoperability and their interrelationships, as well as the business processes and systems to achieve integration, would contribute greatly to eGovernment progress and ultimate success.

\subsubsection{Proliferation of Information and the Challenge to Judiciously Access and Manage Information}

The transformational eGovernment project manager faces, from the project outset, the onerous task of compiling indigenous information associated with managing a project. The project manager has to develop and manage all the detail associated with the processes, dates, tasks, costs, and people. She or he spends his time addressing these requirements and serving another master rather than "getting the job done" and driving the project to success. However, these labours apply to both internal and external activities, constantly focusing on administration and chasing estimates and managing relationships with the governance committees instead of being the prime user of this information. He collects and reports and becomes subservient to information management. This has been a traditional onerous effort by the project manager and she or he becomes mired in the numbers and irrelevant measures by running to placate the bookkeepers and governance players who usually 
are not wedded to the product output. (Hence the interest in the tiresome, nagging detail, and not necessarily relevant administrivia.)

The transformational eGovernment project manager, in order to focus on project results, must optimize the use of available Internet tools to manage the collection, access, and storage of project information. However, the transformational eGovernment project manager can no longer be the focus of the management of information; no longer be the omnipotent information manager. She or he must become the sage in receipt of this data, assembled by others so that he can effectively analyze project process and results. The project manager must "stop rowing and start steering" or risk being swamped by the ubiquitous proliferation of project management information. She or he suffers from the ease to follow the bureaucratic requirements instead of challenging them in the name of product success and outcome. She or he unwittingly becomes the bottleneck of information - in and out; a key stakeholder who needs it most. Other people must assemble and manage the changing and interdependent data, so that the project manager as prime user may read and analyze the information, and no longer "feed the beast."

The management of transformational eGovernment information must use Internet-based and technological tools to harness the power collective intelligence requires. Rather than being a handler of information, the transformational eGovernment project manager must become a key intelligent user that understands the social, cultural, and economic information environment in which transformational eGovernment operates. The transformational eGovernment project manager must prioritize results over processes, and be resolved to use the project information to detect and solidify unstated assumptions and "blind alleys" and interfering governance committee members not committed to the final product.

A broader project management methodology could benefit from the aid of better information and support in managing the interrelationships, location, and access of information as it pertains to all facets of project management; this includes the horizontal and user-related content information, as well as the process-related information required to manage the project itself. Content information would also assist in assessing the implications of changing and evolving requirements, users, and stakeholder and governance committee reporting requirements.

\subsubsection{Lack of a Comprehensive Holistic Approach to Project Management as the Driving Force}

In the management of transformational eGovernment projects there are very few material individual or group incentives for performance; albeit there is a long-established commitment to public service. The individual driving criteria may erroneously be to the mechanistic project management reporting scheme and not to the project success; reporting successfully on measures such as timing or cost controls rather than on results.

Concomitantly, few government organizations have created a "risk culture" that rewards wellmanaged risk taking within the domain of transformational eGovernment project management. As a result, the project manager tends to operate in a cocoon of project methodology processes that 
demonstrate performance and afford protection against possible criticism; the propensity to hide behind governance committees and their announced performance measures.

Transformational eGovernment project managers and those organizations with related responsibilities for project contracting and associated decision-making often become entangled in project management methodology processes such as "earned value management" (EVM) - esoteric to all except some specialists. Yet there is no process dedicated to the realization of project results by the transformational eGovernment project manager.

Furthermore, in enterprise-wide government applications, when the project spans numerous departments and agencies (each having varying degrees of interest and accountability), the project manager is often left to be the "driver" and "prime user"; an unnatural occurrence yet imperative for project success. This situation is exacerbated when central agencies or special programs fund the government-wide initiative instead of the participating funders.

The project management scope and tools for overall responsibility for project success could be expanded to recognize the project manager as the holistic driver, negotiator, and consensus builder. In this capacity, he needs authority and information on the delicate interests both overt and unarticulated on the issues and complications that could derail or promote project success. Technology support and an expansion to and recognition of the scope and responsibilities of project management could contribute to project success.

\subsubsection{Limited Access to Vital Subject Matter Expertise}

There is likely no factor that contributes more to the success of any transformational eGovernment project than having an in-depth and complete definition of the project's scope of work and, as importantly, having the ability to identify and measure the inevitable scope changes that occur during the life of the project.

Project management methodologies rely heavily on scope processes, and this includes the use of subject matter expertise. But the methodologies do not recognize the need to build capacity and capability within the project to develop scope and deliver project results based upon pragmatic subject matter expertise.

Instead transformational eGovernment project management methodologies often look to "historical organizations assets" that contain subject matter expertise, rather than having direct interaction with subject matter experts.

To be effective in the development and delivery of transformational eGovernment project management, methodologies must incorporate procedures that broaden and deepen project management skills in managing ICT programs, as demanded by the information and digital age. This includes an adoption of subject matter expertise.

During the management of transformational eGovernment projects, subject matter expertise is often developed by and inculcated into third-party consultants; because of this, they often become 
de facto project managers that hoard critical corporate knowledge. This becomes an issue that must be addressed by transformational eGovernment methodologies.

The project management scope could be expanded to recognize the importance and difficulties in having access to the subject matter expertise within the client area for the project team when and as required. Though these personnel do not form part of the project team, they do influence the success of the project, and in an informationally enhanced environment, a project management methodology could include the facility to identify, manage, and have access to this expertise as required.

\subsubsection{Organizational Environment not presupposed to Enterprise-Wide Transformation}

In transformational eGovernment there are usually a number of groups with a divergence in attitudes that are involved. So there is the potential for problems caused by disparate vested interests. Power struggles can arise from: conservative verses risk-adverse approaches to project management; personal and organizational fear of the loss of power, authority, and influence; and ineffective communications around the boundaries and interfaces of impacted organizations. In some cases, organizations are dedicated to maintaining existing parochial organizational arrangements and they are diametrically opposed to operational change.

The project management scope could be expanded to recognize the interdependencies and breadth of a government enterprise, and could use technology to help tag and identify the relationships and associated transformational eGovernment activities.

\section{Next Steps}

In addition to proposing enhancements to project management that include technological support to address the compendium of ten challenges, along with a deliberate intentional focus on results versus administration. This paper proposes the need to examine the inclusion of existential leadership to address the human side of the enterprise. The critical aspects of existential change leadership are the content of change, and the decisions and actions that will produce the change results and outcomes: content, people, and process (Anderson, D. 2010). Conscious existential change leadership should be tightly linked to enhanced project management to produce a unified, integrated eGovernment transformation strategy. In transformational eGovernment there are wellknown challenges and barriers to enhanced project management. But in existential change leadership there are internal and external drivers and resistants that are more subtle, difficult to perceive or understand, and often insidious.

Enhanced project management must become a pragmatic business discipline that is anchored on a strategic, conceptual, theoretical model and an integrated, tactical, and operational management framework. Conscious existential change leadership deals with planned and revolutionary change which is the antithesis of organizational continuity and stabilization. Its discipline is visioning, 
behaviour changing, and mind-set altering; all of which are based on a set of theoretical principles and a change leadership road map.

Both disciplines center around portfolio agendas; planning and execution processes; standard structures and practices for designing, implementing and monitoring project and change efforts; project and change centres of excellence; subject matter experts; and strategic management offices. Both are equipped with specific proven theoretical and methodological frameworks to guide practitioners and stakeholders. Both rely heavily on conscious and enlightened leadership to achieve transformational results.

Integration of conscious existential change leadership and enhanced project management is paramount because each discipline brings a specialized perspective to the common essence and key elements of revolutionary change initiatives, and transformational project initiatives; they are the common essentials of content, people, and processes.

It is proposed that the amalgamation of these two disciplines will effectively respond to the inexorable acceleration demands of transformational eGovernment. Specifically, by overcoming the constraints and risks that have impeded eGovernment progress, and by capitalizing on eGovernment opportunities that have remained so elusive.

Enhanced project management will resolve a compendium of ten operational and technical challenges; conscious existential change management will address market, business, organizational and cultural imperatives, and leader and employees' mindsets and behaviour.

Transformational eGovernment project management and change management disciplines include a tactical and operational framework comprised of a project roadmap (Ackerman Anderson, 2010) and a set of targeted compendium of eGovernment challenges and barriers.

The enhanced project management framework remains prescriptive in so far as it recommends activities that should be performed and results that should be achieved; all with a comprehensive specificity and a high level of in-depth exactitude. The basis for this type of framework is that the objective of enhanced project management is predicated on a fully committed project sponsor; defined and articulated stakeholder requirements; multi-level management support; capacity to effective plan, execute, and monitor project activities; and fully defined project results and outcomes.

The objective thus defined enables the integration of the framework tools and techniques to create the project initiation, a project charter, and a preliminary project scope, schedule, and cost scenario. In this way the project content is defined, an implementation plan is developed, and project assumptions and constraints are determined.

\section{Conclusion}

When an organization introduces a change within a project or initiative, that change needs to be effectively managed on both the technical side and the people side. A technical side focus ensures that the change is developed, designed, and delivered effectively. The discipline of enhanced project 
management provides the structure, processes, and tools to make this happen. A people side focus ensures that the change is embraced, adopted, and utilized by the employees who have to do their jobs differently as a result of the project. The discipline of existential change leadership would provide the structure, processes, and tools to make this happen.

Each discipline addresses the key result areas in its particular domain. Enhanced project management confronts the generic compendium of ten barriers and challenges to transformational projects. Existential change leadership responds to the leadership principles and common mistakes that are endemic to transformational change initiatives.

Enhanced project management and existential change leadership would both aim to increase the likelihood that projects and initiatives deliver the intended results and outcomes. While each discipline can function independently, the most effective approach is to integrate existential change leadership and enhanced project management to create a unified approach to implementing change on the technical front and people side front.

The interfaces between project management and change management overlap, and they are certainly interdependent when it comes to successfully delivering value by supporting the strategic initiatives of the business.

Project management is key when it comes to initiating, planning, executing, and monitoring the project activities and deliverables. They ensure a strong solution design backed up with detailed project plans.

Existential change leadership would prepare the organization for the change impact, manage the transition from how we do things today to how they will be done tomorrow, and put special efforts into reinforcing and anchoring the change into the everyday work and life of the organization.

Critical tools in project management are the project charter, business case, budget estimations, a breakdown of the work structure, resource allocations, scheduling, and tracking. Key tools in existential change management are organizational assessments, stakeholder mapping and interventions, communication and coaching plans, training programs, sponsorship road maps, and reinforcement activities.

This research has shown that transformational eGovernment is not living up to promises made; progress is stalling and project failure rates are high. The conclusion is that project management methodologies, originally designed to address the industrial and manufacturing age, do not adequately respond to the needs of today's eGovernment initiatives. They have to be revamped from an administrative compliance methodology to a results-based accountability methodology. Project management has not yet evolved to a state where it can become a force in the solution. It does not bring value from technology and does not facilitate radical changes to organizational arrangements, reengineered business processes, or more client-focused human resource behaviour. This failing introduces the possibility of considering the use of an informationally enhanced project management methodology, along with existential change leadership, to potentially address some of 
these issues and highlight the need for technological support within the project management discipline.

What remains is the challenge to build an enhanced project management methodology. Accelerating the design of a fully developed enhanced project management approach for the digital age would harmonize both the project and change management disciplines, put results ahead of administration, and promote the benefits of innovative change, and deliver eGovernment and ICT project success.

\section{References}

Accenture. (2005). Leadership in Customer Service: New Expectations, New Experiences (2005), http://www.accenture.com/Countries/Canada/Services/By_Subject/Customer_Relationship_Manag ement/R_and_I/LeadershipNewExperiences.htm

Accenture. (2006). Leadership in Customer Service: Building the Trust (2006), http://www.accenture.com/Global/Services/By_Industry/Government_and_Public_Service/PS_Glo bal/R_and_I/BuildingtheTrustES.htm

Accenture. (2007). Leadership in Customer Service: Delivering on the Promise, http://nstore.accenture.com/acn_com/PDF/2007LCSDelivPromiseFinal.pdf

Ackerman Anderson, L., Anderson, D. (2010). The Change Leader's Roadmap: How to Navigate your Organization's Transformation, Pfeiffer, Wiley Imprint, USA

Aikins, S. K. (2012a). Foreword, Managing E-Government Projects: Concepts, Issues and Practices, IGI Global, Hershey, PA, USA.

Aikins, S. K. (2012b). Preface, Managing E-Government Projects: Concepts, Issues and Practices, IGI Global, Hershey, PA, USA.

Aikins, S. K. (2012c). Improving E-Government Project Management: Best Practices and Critical Success Factors, Managing E-Government Projects: Concepts, Issues, and Best Practices, Information Science Reference (IGI Global), Hershey, Pennsylvania, USA.

Aikins, S. K. (editor). (2012d). Managing E-Government Projects: Concepts, Issues, and Best Practices, Information Science Reference (IGI Global), Hershey, Pennsylvania, USA.

Anderson, D., Ackerman Anderson, L. (2010). Beyond Change Management: How to Achieve Breakthrough Results through Conscious Change Leadership, Pfeiffer, Wiley Imprint, USA

Arif, M. (2008). Customer Orientation in eGovernment Project Management: A Case Study, The Electronic Journal of eGovernment, Vol.6, Iss.1, pp.1-10.

BCS Thought Leadership. (2005). Why are Complex IT Projects Different? Debate, Available at: www.bcs.org/server.php?show=conWebDoc.2619 (Accessed on March 16, 2009).

British Computer Society (BCS). (2004). Parliamentary Report on IT Project Waste Management of IT Projects: Making IT Deliver for Department of Work and Pension Customers, http://www.bcs.org/content/conWebDoc/1762, August 26, 2004. 
Burke, W. (2014). Organization Change: Theory and Practice, 4th Edition, Sage Publications, Inc.

Caswey, T., Deszca, G., Ingols, C. (2016). Organizational Change: An Action-Oriented Toolkit. Sage Publications, Inc.

Dawes, S. S. (2009). Governance in the digital age: A research and action framework for an uncertain future, Government Information Quarterly 26, pp.257-264.

Elliman, T. \& Irani, Z. (2007). Establishing a framework for eGovernment research: project VIEGO, 'Transforming Government: People, Process and Policy,' Vol.1, Iss.4; p.364.

Fraser, S. (2006). Report of the Auditor General of Canada to the House of Commons, Chapter 3, Large Information Technology Projects, http://www.oagbvg.gc.ca/internet/English/parl_oag_200611_03_e_14971.html, November 2006.

Furlong, S., Al-Karaghouli, W. (2011, January). Delivering Professional Projects: The Effectiveness of Project Management in Transformational Initiatives, Emerald Publishing.

Furlong, S. (2012). Project Management: An eGovernment Driver? Handbook of Research on E-Government in Emerging Economies: Adoption, E-Participation, and Legal Frameworks, IGI Global, University of Botswana, http://www.igi-global.com.

Furlong, S. (2011). Transformational eGovernment Success through Enhanced Project Management, Ph.D. Thesis, Liverpool, United Kingdom.

Gauthier, J., Lavagnon, A. (n.d.). Foundations of Project Management Research: An Explicit and Six-Facet Ontological Framework, Project Management Journal, Vol. 43, No. 5, pp. 5-23, Project Management Institute.

Government of Canada Foreign Affairs and International Trade Canada. (2006). Government On-Line Final Report, http://www.dfait-maeci.gc.ca/department/gol-annual-report-en.asp, August 30, 2006.

Heeks, R. (2008). eGovernment for Development - Success and Failure in eGovernment Projects, eGovernment for Development Information Exchange, coordinated by the University of Manchester's Institute for Development Policy and Management, http://www.egov4dev.org/success/sfrates.shtml

Irani, Z., Al-Sebie, A., \& Elliman, T. (2006). Transaction Stage of e-Government Systems: Identification of its Location \& Importance, Proceedings of the 39th Hawaii International Conference on System Sciences.

Janowski, T., Estevez, E., \& Ojo, A. (2007). A Project Framework for e-Government, United Nations International Institute for Software Technology, UNU-IIST Report No.359, April 2007.

Kamal, M., Weerakkody, V., \& Irani, Z. (2011). Analyzing the role of stakeholders in the adoption of technology integration solutions in UK local government: An exploratory study, Government Information Quarterly 28 (2011), pp.200-210.

Kerzner, H. (2001). Project Management: A Systems Approach to Planning, Scheduling and Controlling, Seventh Edition, John Wiley and Sons Inc., USA.

Marchewka, J. (2015). Information Technology Project Management Fifth Edition: Providing Measurable Organizational Value, John Wiley \& Sons, Inc., USA. 
Misuraca, G. (2009). e-Government 2015: exploring m-government scenarios, between ICT-driven experiments and citizen-centric implications, Technology Analysis \& Strategic Management, Vol.21, No.3, April 2009, pp.407-424.

Movahedi, B., Tan, R-X., \& Lavassani, K. M. (2010). Organizational Development in Electronic Government Adoption: A Process Development Perspective, International Journal of Electronic Government Research 7 (1), pp.51-63, January - March 2011.

Nordfors, L., Ericson, B., Lindell, H., \& Lapidus, J. (2009). eGovernment of Tomorrow - Future Scenarios for 2020, Gullers Group, Sweden.

Office of Government Commerce (OGC). (2009). Managing successful projects with PRINCE2 Projects In Controlled Environments, TSO London, Office of Government Commerce, The Stationery Office 2009.

Organisation for Economic Cooperation and Development (OECD). (2001). The Hidden Threat to EGovernment: Avoiding large government IT failures, Public Management website, Paris, France, http://www.oecd.org.puma, March, 2001.

Oxford Institute. (2007). Breaking Barriers to eGovernment: Overcoming obstacles to improving European public services, eGovernment Unit, DG Information Society and Media, European Commission, December

23 ,

2007, http://www.egovbarriers.org/downloads/deliverables/solutions_report/Solutions_for_eGovernment .pdf

PRINCE2 Pocketbook. (2009). TSO Information and Publishing Solutions, Norwich, UK.

Project Management Institute (PMI), Inc. (2008). A Guide to the Project Management Body of Knowledge, (PMBOK), 2008, 4th edition, Newtown Square, Pennsylvania, USA 19073-3229.

Roy, J. (2006). E-Government in Canada: Transformation for the Digital Age, University of Ottawa Press.

Sharif, A. \& Irani, Z. (2010). The logistics of information management within an eGovernment context, Journal of Enterprise Information Management, Emerald Group Publisher, Vol.23, Iss.6, pp.694-723.

Schwester, R. (2009). Examining the Barriers to e-Government Adoption, Electronic Journal of

e-Government, Vol.7, Iss.1, 2009, pp.113-122.

Tidd, J., Bessant, J. (2013). Managing Innovation: Integrating Technological, Market and Organizational Change, Fifth Edition John Wiley \& Sons Ltd, United Kingdom

United Nations. (2008). UN E-Government Survey 2008 From E-Government to Connected Governance, Department of Economic and Social Affairs, Division for Public Administration and Development Management, United Nations, New York.

United Nations. (2010). E-Government Survey 2010 - Leveraging e-government at a time of financial and economic crisis, United Nations Department of Economic and Social Affairs, United Nations, New York, http://www2.unpan.org/egovkb/global_reports/10report.htm

Weerakkody, Vishanth. (2009). Handbook of Research on ICT Enabled Transformational Government: A Global Perspective, Information Science Reference, New York, Brunel University 
Weerakkody, V., Janssen, M. \& Dwivedi, Y. K. (2011). Transformational change and business process reengineering (BPR): Lessons from the British and Dutch public sector, Government Information Quarterly 28 (2011), pp.320-328.

Wells, H. (2012). How Effective are Project Management Methodologies? An Explorative Evaluation of Their Benefits in Practice, Project Management Journal, Vol. 43, No. 6, pp. 43-58, Project Management Institute.

West, D. (2007). Global E-Government, Brown University, Rhode Island, USA, August 2007.

World Bank. (2002). The E-Government Handbook for Developing Countries, Centre for Democracy and Technology, Washington, USA.

Young, R., Young, M., Jordan, E., O'Connor, P. (2012). Is strategy being implemented through projects? Contrary evidence from a leader in New Public Management, International Journal of Project Management 30 (2012). pp. 887-900,

Zhao, F., Scavarda, A, \& Waxin, M. (2012). Key issues and challenges in e-government development: An integrative case study of the number one eCity in the Arab world, Information, Technology \& People, Vol 25 No. 4, 2012, pp. 395-422, Emerald Group Publishing Limited.

Ziemann, J., \& Loos, P. (2009). Transforming Cross-Organisational Processes between European Administrations: Towards a Comprehensive Business Interoperability Interface, Handbook of Research on ICT-Enabled Transformational Government: A Global Perspective, Information Science Reference, London, UK, 2009, pp.93 -116.

\section{About the Author}

\section{Shauneen Furlong}

Shauneen Furlong is an independent consultant and part-time professor who lectures on eGovernment and project management with the University of Toronto and University of Ottawa. Over the last couple of years, she has presented and worked in the United Kingdom (Brunel, London), Middle East (Bahrain, Dubai), Europe (Austria, Greece, Italy, Turkey), Africa (Morocco, Tanzania), Egypt, China (Macao), Canada, and Washington, and with the United Nations, World Bank and Conference Board of Canada.

Dr. Furlong has executive level management experience in a number of Government of Canada central agencies and departments over a period of 20 years, lastly as Executive Director, Government On-Line, Government of Canada.

She has published articles and peer reviewed papers for international journals and conferences. She was awarded an IBM Fellowship, and has a Ph.D. in Computer Science; an MBA in Project Management; a BA in Philosophy; and is a Project Manager Professional (PMP).

Dr. Furlong was nominated by IT World Canada as being one of Canada's key eGovernment drivers, and was profiled by Computer World Canada. 